\title{
Study on Internet Use and Family Education Style of Middle School Students
}

\author{
Zhongfu Li \\ College of Media and Communication, Zaozhuang University \\ Zaozhuang, China 277160
}

\begin{abstract}
The popularity of the Internet, especially the mobile Internet, has changed people's study and life style. While the Internet brings convenience to people's life and study, a series of problems due to inappropriate access to internet are also becoming increasingly obvious, which makes it difficult for the middle school students with poor self-control ability to resist the temptation of the Internet and brings about adverse effects on their studies, families as well as their physical and mental health. In this paper, the students of Zaozhuang No. 1 Middle School were investigated by self-compiled questionnaire based on using the statistical methods of the Scale of Family Education Style and Scale of Chinese Internet Addiction. The results showed that there were differences in the gender and urban-rural dimensions of the network use among middle school students, and the use of Internet by middle school students was related to the family education style.
\end{abstract}

Keywords-Middle school students; Internet use; family education style

\section{INTRODUCTION}

Internet use covers a wide range, including searching information on the Internet, interpersonal communication on the Internet, playing online games, and using various online resources, etc. The degree of use includes both normal use and internet addiction. Parenting style refers to the methods and forms used by the parents in raising and educating the children, which is a generalization of the characteristics of parents' various parenting behaviors and a kind of behavior style with relative stability [1]. Parenting style includes the concept, behavior and attitude of parents to educate their children, which is a kind of fixed behavior pattern and behavior tendency in raising their children. This paper takes the middle school students as the subject. They have intense and heavy pressure in study and usually take the Internet as one of the main ways of study, relaxation and entertainment. The research objects are not purely the teenagers who are addicted to the Internet but they are studied according to the different levels of use by taking the level of use as the standard.

\section{A. Investigation and Analysis on the Current Status of Internet Use of Middle School Students}

Nowadays, the rapid development and increasing popularity of Internet have led to a sharp increase in the number of Internet users. According to the data from 43rd Internet Development Survey released by the China Internet Network Information Center in 2019, the number of Internet users in China reached 829 million and the popularity rate reached $59.6 \%$ as of December 2018. Among them, the student group occupied the highest proportion, reaching $25.4 \%$, and especially the proportion of middle school students was the highest [2]. In the proportion of online games users, the users at the age of 10 to 19 had occupied the highest proportion. In addition, according to the report on the third investigation of Internet addiction of China Youth Association for Network Development, about $14.1 \%$ of urban youth netizens in China were addicted to Internet; Among the urban teenagers who were not addicted to Internet, about $12.7 \%$ of them had the tendency of internet addiction. As for the age group with excessive use of internet and internet addiction, teenagers at the 18 years old or so occupied the highest proportion. However, seen from the educational background structure of internet users, high school had occupied the highest proportion, followed by the middle school [3].

\section{B. Network Usage Degree and Gender Distribution Among Middle School Students}

TABLE I ANALYSIS OF GENDER AND NETwork UsAge DEgREE

\begin{tabular}{lllll}
\hline & Gender & \multicolumn{3}{l}{ Usage degree } \\
\cline { 2 - 5 } & Male & Female & Normal & Degree \\
\hline $\begin{array}{l}\text { Number of } \\
\text { persons (person) }\end{array}$ & 58 & 48 & 48 & 58 \\
\hline Percentage & $54.7 \%$ & $45.3 \%$ & $45.3 \%$ & $54.7 \%$ \\
\hline
\end{tabular}

The total score of network use is divided by 46, normal use $(<46)$ and overuse $(\geq 46)[4]$

C. Differences in the Gender Dimension for Internet Usage of Middle School Students

TABLE II TEST ON DIFFERENCE IN AVERAGE SCORES OF DIFFERENT GENDERS IN NETWORK USAGE DEGREE

\begin{tabular}{lllll}
\hline & Male $(\mathrm{n}=58)$ & $\begin{array}{l}\text { Female } \\
(\mathrm{n}=48)\end{array}$ & $\mathrm{t}$ & $\mathrm{p}$ \\
& $\mathrm{M} \pm \mathrm{SD}$ & \multicolumn{3}{c}{} \\
\hline Total score & $51.93 \pm 14.17$ & $45.08 \pm 11.16$ & 2.720 & 0.008 \\
\hline
\end{tabular}

As can be seen from the above table, the average score of male students' network usage (51.93) was higher than that of female students (45.08), and the significance level was 0.008 , which was far lower than 0.05 . The difference was significant, which indicated that the middle school students' network usage degree had significant difference in terms of gender. 
D. Difference of Middle School Students' Network Use in Urban and Rural Dimensions

TABLE III TEST ON DIFFERENCE IN AVERAGE SCORES OF DIFFERENT RESIDENTIAL AREAS IN NETWORK USAGE DEGREE

\begin{tabular}{llllll}
\hline & $\begin{array}{l}\text { Urban } \\
(\mathrm{n}=40)\end{array}$ & $\begin{array}{l}\text { Rural area } \\
(\mathrm{n}=66)\end{array}$ & $\mathrm{p}$ \\
\cline { 1 - 3 } $\mathrm{M} \pm \mathrm{SD}$ & \multicolumn{3}{c}{$\mathrm{p}$} \\
\cline { 1 - 3 } Total & $52.85 \pm 13.34$ & $46.39 \pm 12.74$ & 2.484 & 0.015
\end{tabular}

As can be seen from the above table, the urban students' Internet usage degree (52.85) was greater than that of the rural students (46.39), and the significance level was 0.015 , which was less than 0.05 . The test results were significant, which indicated that the middle school students' network usage degree had significant difference in terms of urban and rural dimensions.

\section{INVESTIGATION AND ANALYSIS OF MIDDLE SCHOOL STUDENTS' FAMILY EDUCATION STYLE}

In this paper, the Scale of Family Education Style is adopted to divide the parents' educational attitude and behavior into eleven dimensions. If a certain dimension exceeds the normal scores, it can be determined that the educational style has this tendency.

\section{A. Differences of Parenting Style for Middle School Students in the Gender Dimensions}

When comparing differences in parenting style in the gender dimensions, because it involved two levels of one variable, the scores of the male and the female were divided into two groups according to gender. Each group could be regarded as a continuous variable obeying the normal distribution, and the total variance was unknown. The samples of students of different genders could be regarded as independent from each other, and the t-test of two independent samples can be used. Also when it comes to the urban and rural dimensions, the $t$ test method of two independent samples can also be used to analyze the difference in average scores of family education modes in various dimensions.

TABLE IV TEST ON DIFFERENCE IN AVERAGE SCORES OF PARENTING STYLE AMONG DIFFERENT GENDERS IN VARIOUS DIMENSIONS

\begin{tabular}{|c|c|c|c|c|}
\hline & Male $(\mathrm{n}=58)$ & Female $(\mathrm{n}=48)$ & \multirow[t]{2}{*}{$\mathrm{t}$} & \multirow[t]{2}{*}{$\mathrm{p}$} \\
\hline & $\mathrm{M} \pm \mathrm{SD}$ & & & \\
\hline m Emotional warmth and understanding & $53.74 \pm 8.83$ & $54.87 \pm 9.70$ & -0.62 & 0.53 \\
\hline $\mathrm{m}$ Excessive interference and protection & $35.53 \pm 5.45$ & $33.08 \pm 5.95$ & 2.20 & 0.02 \\
\hline $\mathrm{m}$ Rejection and denial & $12.75 \pm 3.57$ & $12.79 \pm 4.82$ & -0.03 & 0.96 \\
\hline m Severe punishment & $12.18 \pm 4.04$ & $12.10 \pm 3.49$ & 0.11 & 0.90 \\
\hline $\mathrm{m}$ Preference for subjects & $9.98 \pm 2.73$ & $11.04 \pm 2.71$ & -1.99 & 0.04 \\
\hline f Emotional warmth and understanding & $49.32 \pm 8.61$ & $49.85 \pm 9.06$ & -0.30 & 0.76 \\
\hline f Severe punishment & $16.91 \pm 5.22$ & $15.64 \pm 5.52$ & 1.21 & 0.22 \\
\hline f Excessive interference & $20.25 \pm 3.20$ & $19.27 \pm 3.92$ & 1.42 & 0.16 \\
\hline f Preference for subjects & $9.00 \pm 2.79$ & $9.95 \pm 3.04$ & -1.68 & 0.05 \\
\hline $\mathrm{f}$ Rejection and denial & $9.32 \pm 3.46$ & $8.62 \pm 2.67$ & 1.15 & 0.25 \\
\hline f Excessive protection & $11.03 \pm 2.73$ & $11.14 \pm 2.70$ & -0.20 & 0.83 \\
\hline
\end{tabular}

It can be seen from the above table that the score of male students in the dimensions of mother's emotional warm and understanding, rejection and denial, preference for subjects, father's emotional warm and understanding, preference for subjects, and excessive protection is lower than that of the female students. However, the score of male students in the dimensions of mother's excessive interference and excessive protection, severe punishment, father's severe punishment, and excessive protection is higher than that of the female students. Besides through the t-test of independent samples, in the three dimensions of mother's excessive interference and excessive protection $(\mathrm{P}=0.029<0.05)$, preference for subjects $(\mathrm{P}=0.049$ $<0.05)$, fathers' preference for subjects $(\mathrm{P}=0.05)$, the tests are significant. The parents generally have excessive interference and excessive protection against boys while show preference over girls in the process of education.

\section{B. Differences of Parenting style for Middle School Students in Urban and Rural Dimensions}

TABLE V TEST ON DIFFERENCE IN AVERAGE SCORES OF PARENTING STYLE IN DIFFERENT RESIDENTIAL AREAS IN VARIOUS DIMENSIONS

\begin{tabular}{|c|c|c|c|c|}
\hline & Urban area $(n=40)$ & Rural area $(n=66)$ & $\mathrm{t}$ & $\mathrm{p}$ \\
\hline & $\mathrm{M} \pm \mathrm{SD}$ & & & \\
\hline $\begin{array}{l}\text { m Emotional } \quad \text { warmth } \quad \text { and } \\
\text { understanding }\end{array}$ & $52.27 \pm 10.30$ & $55.45 \pm 8.33$ & -1.73 & 0.85 \\
\hline $\begin{array}{l}\mathrm{m} \text { Excessive interference and } \\
\text { protection }\end{array}$ & $36.05 \pm 5.70$ & $33.43 \pm 5.65$ & 2.290 .02 & \\
\hline m Rejection and denial & $13.85 \pm 4.26$ & $12.12 \pm 3.99$ & 2.100 .03 & \\
\hline m Severe punishment & $12.80 \pm 4.45$ & $11.75 \pm 3.29$ & 1.38 & 0.17 \\
\hline
\end{tabular}




\begin{tabular}{lllll}
\hline & & & \\
\hline m Preference for subjects & $9.85 \pm 3.05$ & $10.83 \pm 2.51$ & -1.79 & \\
\hline f Emotional warmth and understanding & $48.17 \pm 9.72$ & $50.40 \pm 8.12$ & -1.27 & 0.07 \\
\hline f Severe punishment & $17.65 \pm 6.52$ & $15.54 \pm 4.40$ & 1.98 & \\
\hline f Excessive interference & $20.60 \pm 3.79$ & $19.32 \pm 3.36$ & 1.79 & 0.20 \\
\hline f Preference for subjects & $9.32 \pm 3.12$ & $9.50 \pm 2.83$ & -0.29 & 0.05 \\
\hline f Rejection and denial & $10.27 \pm 3.82$ & $8.24 \pm 2.34$ & 3.03 & 0.76 \\
\hline f Excessive protection & $11.20 \pm 3.00$ & $11.01 \pm 2.53$ & 0.33 & 0.00 \\
\hline
\end{tabular}

It can be seen from the above table that the score of urban students in the dimensions of mother's emotional warm and understanding, preference for subjects, father's emotional warm and understanding, severe punishment, and preference for subjects is lower than that of the middle school students in rural areas. However, the score of urban students in other dimensions is greater than that of the middle school students in rural areas. In addition, through the t-test of independent samples, there is a significant difference in mother's excessive interference and excessive protection $(\mathrm{P}=0.02<0.05)$, rejection and denial $(\mathrm{P}=0.03<0.05)$, and father's rejection and denial $(\mathrm{P}=0.00<0.05)$. The score of urban students in these dimensions is greater than that of the middle school students in rural areas. This indicates that parents in urban areas educate their children more severely than the parents in rural areas, and that the middle school students in urban areas are more restrained and interfered with by their parents than the middle school students in rural areas.

\section{THE RELATIONSHIP BETWEEN THE NETWORK USE OF MIDDLE SCHOOL STUDENTS AND THE WAYS OF FAMILY EDUCATION}

\section{A. Comparison of the Ways of Family Education Among Middle School Students with Different Network Usage Degree}

Compare the differences of high school students' network usage degree in various dimensions of family education, and divide the usage degree of the variables into two levels which were normal use and overuse. The average scores of each dimension of family education were also compared with the t-test method of independent samples.

TABLE VI TEST ON DIFFERENCE IN AVERAGE SCORES OF FAMILY EDUCATION METHODS WITH DIFFERENT NETWORK USAGE DEGREE IN VARIOUS DIMENSIONS

\begin{tabular}{|c|c|c|c|c|}
\hline & Normal $(n=48)$ & Excessive $(n=58)$ & \multirow[t]{2}{*}{$\mathrm{t}$} & \multirow[t]{2}{*}{$\mathrm{p}$} \\
\hline & \multicolumn{2}{|l|}{$\mathrm{M} \pm \mathrm{SD}$} & & \\
\hline $\begin{array}{l}\text { m Emotional warmth and } \\
\text { understanding }\end{array}$ & $54.27 \pm 9.32$ & $54.24 \pm 9.19$ & 0.01 & 0.55 \\
\hline $\begin{array}{l}\mathrm{m} \text { Excessive interference } \\
\text { and protection }\end{array}$ & $34.41 \pm 5.45$ & $34.43 \pm 6.09$ & 0.01 & 0.99 \\
\hline m Rejection and denial & $10.62 \pm 3.34$ & $11.89 \pm 4.04$ & -1.83 & 0.04 \\
\hline $\mathrm{m}$ Severe punishment & $11.93 \pm 3.40$ & $12.32 \pm 4.09$ & -0.52 & 0.60 \\
\hline $\mathrm{m}$ Preference for subjects & $10.77 \pm 2.65$ & $10.20 \pm 2.83$ & 1.04 & 0.29 \\
\hline $\begin{array}{l}\text { f Emotional warmth and } \\
\text { understanding }\end{array}$ & $50.37 \pm 8.69$ & $49.89 \pm 8.87$ & 0.86 & 0.41 \\
\hline f Severe punishment & $16.04 \pm 5.34$ & $16.58 \pm 5.43$ & -0.51 & 0.60 \\
\hline f Excessive interference & $20.02 \pm 3.74$ & $19.63 \pm 3.43$ & 0.54 & 0.58 \\
\hline f Preference for subjects & $9.50 \pm 2.74$ & $9.37 \pm 3.10$ & 0.21 & 0.83 \\
\hline f Rejection and denial & $7.93 \pm 2.11$ & $9.46 \pm 3.53$ & -2.36 & 0.03 \\
\hline f Excessive protection & $10.70 \pm 2.41$ & $11.39 \pm 2.91$ & -1.30 & 0.19 \\
\hline
\end{tabular}

It can be seen from the above table that the average score of the normal use group is higher than that of the overuse group in the dimensions of mother's emotional warm and understanding, mother's preference for subjects, father's emotional warm and understanding, and father's preference for subjects, which indicates that if the parents educate their children with warm and understanding and pay more attention and care to them, it

is easier for their children to form an attitude of scientific and normal use of the network.

\section{B. Correlation Analysis between Middle School Students' Internet Use and Father's Way of Education}

Pearson product-moment correlation is used to conduct correlation analysis of each dimension of the father's education style and the total score of the network usage degree.

TABLE VII PEARSON CORRELATION ANALYSIS OF FATHER'S WAY OF EDUCATION AND THE NETWORK USAGE DEGRE

\begin{tabular}{ll}
\hline \multicolumn{1}{c}{ Father's way of education } & Total score of network usage degree \\
Emotional warmth and understanding & -0.138 \\
Severe punishment & 0.151 \\
Excessive interference & -0.017 \\
Preference for subjects & -0.055 \\
Rejection and denial & 0.215 \\
Excessive protection & 0.188
\end{tabular}

As can be seen from the table, in father's education style, the three dimensions of emotional warmth and understanding,

excessive interference, and preference for subjects are negatively correlated with the network usage degree. However, the $\mathrm{P}$ value is greater than 0.05 , so the correlation is not 
significant and has not achieved the statistical significance. The three dimensions of severe punishment, refusal and denial, and excessive protection are positively correlated with the network usage degree, with the refusal and denial $(\mathrm{P}=0.027<0.05)$ and having the statistical significance. This indicates that when the father adopts the strict education methods in the education process, the more he refuses and denies his children, the easier it is for his children to use the network unscientifically.

\section{Correlation Analysis between Middle School Students' Internet Use and Mother's Way of Education}

TABLE VIII PEARSON CORRELATION ANALYSIS OF MOTHER'S WAY OF EDUCATION AND THE NETWORK USAGE DEGREE

\begin{tabular}{lll}
\hline Mother's way of education & $\begin{array}{l}\text { Total score of network usage } \\
\text { degree }\end{array}$ \\
$\begin{array}{l}\text { Emotional warmth and } \\
-0.072\end{array}$ & \\
$\begin{array}{l}\text { Exderstanding insive interference and } \\
\text { protection }\end{array}$ & 0.110 & \\
$\begin{array}{l}\text { Rejection and denial } \\
\text { Severe punishment }\end{array}$ & 0.201 & \\
Preference for subjects & 0.136 & \\
\end{tabular}

As can be seen from the table, in all dimensions of mother's education style, emotional warmth and understanding and preference for subjects are negatively correlated with the total score of network usage degree. Excessive interference and protection, refusal and denial, and severe punishment are positively correlated with the total score of internet usage degree. Among them, the correlation with refusal and denial $(\mathrm{P}=0.036<0.05)$ is significant. Therefore, the mother's adoption of warm and caring education will promote their children to form a scientific and normal attitude towards the use of the Internet, while the overuse of indifferent and rejected education will cause the children to form the habit of over-reliance on the Internet and unscientific use of the Internet.

\section{CONCLUSION}

According to the comparison of different network usage degrees and different parenting styles among middle school students, compared with excessive use of the Internet, the middle school students who normally use the Internet receive more emotional care from their parents in their daily life. They can have good communication with their parents, and obtain more respect and understanding from their parents. In the excessive use of the Internet, the average sore of parents' excessive interference, severe punishment, as well as rejection and denial is higher than that of the normal use of the Internet. This shows that parents often adopt indifferent, strict and unappreciative education methods, and adopt the attitude of refusing, denying or ignoring their children's opinions and suggestions. If they do this for a long term, this may cause children's inferiority and timidity. Children lack the courage to communicate with their parents and seek support from them, and their reasonable demands cannot be met, which will make them feel helpless and frustrated. In reality, if the children fail to get enough understanding and communication from their parents, they are more inclined to look for recognition and warmth in the online world, so they will be too dependent on the virtual world, thus overusing the internet and even becoming addicted to the internet, forming unscientific and unreasonable network usage habits.

Therefore, a good family living environment and a relatively scientific way of education play a very important role in the correct use of the Internet and the healthy development of the body and mind of middle school students.

\section{REFERENCES}

[1] Dexin XIA. The relationship between self-esteem, parental style and the usage degree of online games in Junior middle school students in grade two [D]. Shenyang Normal University, 2012

[2] Statistical Report on China's Internet Development. China Internet Network Information Center (CNNIC), 2019-2.

[3] Report on Internet Addiction among Chinese Teenagers (2009). China Youth Association for Network Development, 2010-2.

[4] JianxiongYAN. Study on the Correlation between Internet Addiction Tendency, Family Function and Parenting Style of High School Students [D]. Hunan Normal University, 2009. 